\title{
AGE-SEX SPECIFIC PREVALENCE OF RADIOGRAPHIC ABNORMALITIES OF THE JOINTS OF THE HANDS, WRISTS AND CERVICAL SPINE OF ADULT RESIDENTS OF THE TECUMSEH, MICHIGAN, COMMUNITY HEALTH STUDY AREA, 1962-1965*
}

\author{
W. M. Mikkelsen, M.D. and I. F. Duff, M.D. \\ Rackham Arthritis Research Unit and Department of Internal Medicine, Medical School \\ and \\ H. J. DODGE, M.D. \\ Department of Epidemiology, School of Public Health, The University of Michigan
}

(Received 3 September 1968; in revised form 13 March 1969; further revised 29 December 1969)

\section{INTRODUCTION}

DURING the examination of participants in the Tecumseh Community Health Study in 1962-1965 (TCHS II), an attempt was made to secure radiographs of the hands and wrists and of the cervical spine as a part of the study of rheumatic disorders in the population.

The purpose of the present paper is to report the principal findings as to the interpretation of the films of those $16 \mathrm{yr}$ of age or older, who were resident in the study area and had radiographs taken for the study of the arthritides in the population.

Since a number of eligible participants were not X-rayed, the question arises as to whether those reported here are a biased sample of the population. Those who were $\mathrm{X}$-rayed did not differ significantly from those who were not X-rayed by any demographic characteristics except for age distribution. Those not X-rayed were significantly younger, for reasons given under 'Methods', below. However, of eligible persons $20 \mathrm{yr}$ of age and over, 95.9 per cent were X-rayed. In addition, there was no selection on the grounds of history or clinical suspicion of the presence of any of the arthritides, and it is our feeling that the group reported here is reasonably representative of the community at large, within the imposed age limits.

\section{METHODS}

The radiographs were taken in the X-ray Department of the Herrick Memorial Hospital where the TCHS Clinic was located. A single film of the posteroanterior

\footnotetext{
* This study was supported by Program Project Grant HE 6378 to The Cardiovascular Research Center, The University of Michigan (Thomas Francis, JR., M.D., Director), from The National Heart Institute, National Institutes of Health and by Grant C.D.-00005 from The U.S. Public Health Service. It is reported for The Research Staff of The Tecumseh, Michigan, Community Health Study.
} 
view of both hands and wrists was taken, employing an average exposure of $0.3 \mathrm{sec}$ at $100 \mathrm{~mA}$ and $46 \mathrm{kVp}$. A film of the cervical spine in fiexion was taken in the lateral view, employing an exposure of $0.1 \mathrm{sec}$ with $200 \mathrm{~mA}$ and $72 \mathrm{kVp}$ for adults and 150 $\mathrm{mA}$ and $72 \mathrm{kVp}$ for children.

It was originally intended to include all participants age $6 \mathrm{yr}$ or older in this program, but following an early review of the films, the extremely low yield of abnormal films in those 6-19 yr of age led to the decision to limit such X-ray examination thereafter to those participants $20 \mathrm{yr}$ of age or older. However, because participants of ages 16-19 yr of age are treated as adults in the general examination procedure, this age group has been included in the present report, when they had X-ray films taken.

Interpretation of the films was made by the three authors, employing the Atlas of Standard Radiographs of Arthritis (F. A. Davis Co., Philadelphia, 1963) as a reference standard. Each film was interpreted independently by at least two of the three investigators. When there was significant disagreement between independent interpretations, the film was reviewed by the three investigators in order to reach a consensus as to the degree and nature of the pathology. In recording the interpretations for purposes of analysis, only the highest grade of a particular type of pathology was recorded, whether it involved one or more than one joint. No attempt was made to record the findings of each joint separately. The presence of other types of pathology, not covered by the Atlas, was recorded without attempt at grading.

For those types of pathology covered by the reference standard, the grading system is one using the code: $0=$ none, $1=$ doubtful, $2=$ minimal, $3=$ moderate and $4=$ severe. Where graded types of pathology are being dealt with prevalence ratios, in per cent, will be calculated as the relationship of the sum of participants with grades, 2, 3 and 4 to the total number of participants $X$-rayed. For ungraded types of pathology, the prevalence ratios will simply state the relative number (per cent) with the condition.

\section{RESULTS}

The estimates of prevalence to follow are based on a total of 4415 participants, unselected by reason of history or clinical suspicion of the presence of one or more of the arthritides. Of these 4415 persons, 2096 or 47.5 per cent were male and 2319 or 52.5 per cent were female. Of the total, only 23 or 0.5 per cent had one or the other, but not both, films taken. Of the 4392 participants who had both films taken, 2044 or 46.6 per cent had no pathology to be seen in either film, 901 or 20.5 per cent had pathology of some type or degree in the hands and wrists, but none in the cervical spine, 257 or 5.9 per cent had pathology seen in the spine film but not in the hand and wrist film, while in the remaining 1190 or 27.1 per cent, pathology of some type or degree was seen in both films. In general, the males showed a greater frequency of pathology than did the female subjects, the relative frequencies being approximately 58 and 49 per cent, respectively.

Of those who had films of the hands and wrists, there were 2093 males and 2314 females. Each sex has been divided in six age groups for the purpose of demonstrating the sex-age specific distributions of pathology.

Since sex specific prevalence (all ages) may show differences which are, in part, a function of differences in age distribution, an age specific adjustment has been carried 


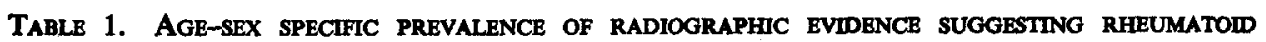
ARTHRTIS OF THE HANDS AND WRISTS, TCHS 1962-1965

\begin{tabular}{|c|c|c|c|c|c|c|c|c|}
\hline Sex & $\begin{array}{l}\text { Age } \\
\text { (yr) }\end{array}$ & \multicolumn{5}{|c|}{ Number of persons graded } & $\begin{array}{l}\text { Number } \\
\text { filmed }\end{array}$ & $\begin{array}{c}\text { Prevalence } \\
(\%)\end{array}$ \\
\hline \multirow[t]{3}{*}{ Males } & $\begin{array}{l}16-24 \\
25-34 \\
35-44\end{array}$ & $\begin{array}{l}275 \\
450 \\
567\end{array}$ & $\begin{array}{l}0 \\
0 \\
0\end{array}$ & $\begin{array}{l}0 \\
0 \\
0\end{array}$ & $\begin{array}{l}0 \\
0 \\
0\end{array}$ & $\begin{array}{l}0 \\
0 \\
1\end{array}$ & $\begin{array}{l}275 \\
450 \\
568\end{array}$ & $\begin{array}{l}0.0 \\
0.0 \\
0.18\end{array}$ \\
\hline & $\begin{array}{c}45-54 \\
55-64 \\
65 \text { or } \\
\end{array}$ & $\begin{array}{l}389 \\
244\end{array}$ & $\begin{array}{l}\mathbf{0} \\
\mathbf{0}\end{array}$ & $\begin{array}{l}0 \\
0\end{array}$ & $\begin{array}{l}2 \\
0\end{array}$ & $\begin{array}{l}\mathbf{0} \\
\mathbf{0}\end{array}$ & $\begin{array}{l}391 \\
244\end{array}$ & $\begin{array}{l}0.51 \\
0.00\end{array}$ \\
\hline & Total & 2088 & 1 & 1 & 2 & 1 & 2093 & 0.19 \\
\hline \multirow[t]{3}{*}{ Females } & $\begin{array}{l}16-24 \\
25-34 \\
35-44\end{array}$ & $\begin{array}{l}297 \\
514 \\
623\end{array}$ & $\begin{array}{l}\mathbf{0} \\
\mathbf{0} \\
\mathbf{0}\end{array}$ & $\begin{array}{l}0 \\
0 \\
0\end{array}$ & $\begin{array}{l}0 \\
0 \\
1\end{array}$ & $\begin{array}{l}\mathbf{0} \\
\mathbf{0} \\
\mathbf{0}\end{array}$ & $\begin{array}{l}297 \\
514 \\
624\end{array}$ & $\begin{array}{l}0.0 \\
0.0 \\
0.16\end{array}$ \\
\hline & $\begin{array}{l}45-54 \\
55-64 \\
65 \text { or } \\
\text { older }\end{array}$ & $\begin{array}{l}375 \\
263 \\
\\
227\end{array}$ & $\begin{array}{l}2 \\
2\end{array}$ & $\begin{array}{l}1 \\
0\end{array}$ & $\begin{array}{l}0 \\
2\end{array}$ & $\begin{array}{l}0 \\
2\end{array}$ & $\begin{array}{l}378 \\
269\end{array}$ & $\begin{array}{l}0.26 \\
1.47\end{array}$ \\
\hline & Total & 2299 & 7 & 3 & 3 & 2 & 2314 & 0.34 \\
\hline
\end{tabular}

* Numerator of ratios are the sum of number in grades 2,3 , and 4.

Age adjusted prevalence ratios: Male 0.19 per cent.

Female 0.33 per cent.

TABLE 2. AGE-SEX SPECIFIC PREVALENCE OF RADIOGRAPHIC EVIDENCE SUGGESTING OSTEOARTHROSIS OF THE HANDS AND WRISTS, TCHS, 1962-1965

\begin{tabular}{|c|c|c|c|c|c|c|c|c|}
\hline \multirow[b]{2}{*}{ Sex } & \multirow{2}{*}{$\begin{array}{l}\text { Age } \\
\text { (yr) }\end{array}$} & \multicolumn{5}{|c|}{ Number of persons graded } & \multirow{2}{*}{$\begin{array}{l}\text { Number } \\
\text { filmed }\end{array}$} & \multirow{2}{*}{$\begin{array}{c}\text { Prevalence } \\
(\%)\end{array}$} \\
\hline & & 0 & 1 & 2 & 3 & 4 & & \\
\hline \multirow[t]{7}{*}{ Males } & $16-24$ & 269 & 6 & 0 & 0 & 0 & 275 & 0.0 \\
\hline & $25-34$ & 385 & 59 & 5 & 1 & 0 & 450 & 1.3 \\
\hline & $35-44$ & 353 & 184 & 29 & 2 & 0 & 568 & 5.5 \\
\hline & $45-54$ & 126 & 163 & 92 & 9 & 1 & 391 & 25.1 \\
\hline & $55-64$ & 27 & 77 & 91 & 43 & 6 & 244 & 57.4 \\
\hline & older & 7 & 29 & 55 & 49 & 25 & 165 & 78.2 \\
\hline & Total & 1167 & 518 & 272 & 104 & 32 & 2093 & 19.5 \\
\hline \multirow[t]{7}{*}{ Females } & $16-24$ & 294 & 3 & 0 & 0 & 0 & 297 & 0.0 \\
\hline & $25-34$ & 479 & 35 & 0 & 0 & $\mathbf{0}$ & 514 & 0.0 \\
\hline & $35-44$ & 430 & 17 & 21 & 2 & 1 & 624 & 3.8 \\
\hline & \multirow{3}{*}{$\begin{array}{l}45-54 \\
55-64 \\
65 \text { or } \\
\text { older }\end{array}$} & 120 & 139 & 96 & 12 & 11 & 378 & 31.5 \\
\hline & & 27 & 62 & 123 & 34 & 23 & 269 & 70.6 \\
\hline & & 1 & 21 & 95 & 74 & 41 & 232 & 90.5 \\
\hline & Total & 1351 & 430 & 335 & 122 & 76 & 2314 & 23.0 \\
\hline
\end{tabular}

* Numerators of ratios are the sum of numbers in grades 2, 3, and 4.

Age adjusted prevalence ratios: Male

19.8 per cent.

Female 22.9 per cent. 
out and appears at the foot of each table. So many different standards of reference age distributions are used by various investigators, that we have used the simplest. We have simply pooled the numbers of males and females of each age category and used this as the standard for calculating the expected numbers from which the age adjusted rates are derived. In no case does the age adjusted rate show any striking difference from the observed sex specific rate, except for degenerative disc disease.

First to be considered is radiographic evidence of rheumatoid arthritis as shown in Table 1. According to our interpretation of these data, evidence of this disease in films of the hands and wrists is rare, but does show the expected sex difference in prevalence ( 0.19 in males and 0.34 per cent in females) and some suggestion of increasing prevalence with increasing age, especially among females. The distribution by grade (all ages) is not remarkable.

The evidence of osteoarthrosis of the hands and wrists is much more common, as will be seen in Table 2. There is an age specific gradient of prevalence for both sexes. Among males the prevalence of osteoarthrosis is higher up through age 44 than in females, but thereafter, the reverse is true so that the slope of the prevalence ratio curve for women starts somewhat later on the age scale, but rises more rapidly thereafter than that of men. The all age prevalence ratio for females ( 23.0 per cent) is higher than that of males (19.5 per cent).

Other lesions of the hands and wrists noted, were simply classified broadly into those probably due to traumatic, congenital or other type of origin. Prevalence of such abnormalities is summarized in Table 3. As for radiographic evidence of lesions

TABLE 3. AGE-SEX SPECIFIC PREVALENCE OF RADIOGRAPHIC EVIDENCE OF LESIONS OF THE HANDS AND WRISTS OTHER THAN RHEUMATOID ARTHRITIS OR OSTEOARTHROSIS, TCHS, 1962-1965

\begin{tabular}{lccccc}
\hline & & & \multicolumn{3}{c}{ Prevalence, per cent of lesions suggesting } \\
origin due to
\end{tabular}

Age adjusted prevalence ratios: Male

13.5 per cent; 1.5 per cent; 0.8 per cent.

Female

4.8 per cent; 1.6 per cent; 0.4 per cent. 
thought to be traumatic in origin, the prevalence ratios were almost three times as great in males as those in females (13.7-5.1 per cent). These ratios in men start at a level of 5 per cent in the youngest group, rise rapidly to the age group 35-44 yr, after which the ratios stabilize between 15 and 18 per cent. In women there is a steady rise in prevalence ratios with age, but only in the three oldest age groups of women do the ratios exceed that of the youngest age group of males. As to prevalence of radiographic evidence of lesions thought to be developmental in origin, there were no age associated patterns, nor differences, between the two sexes. Lesions of other origins were rare and presented no sex or age related patterns.

Cervical spine films of 2090 males and 2310 females were available for evaluation. Two types of lesions were seen frequently. The most commonly occurring was that of degenerative disc disease, as defined by the reference standard. The distribution of the evidence for such lesions is given in Table 4. It will be seen that this condition is slightly more prevalent in men than in women, 18.7 per cent and 16.1 per cent, respectively, but that the difference increases on age adjustment. There is also an age gradient for both sexes; the prevalence ratio curve is somewhat steeper for men, but not to a statistically significent degree (logit method).

The next most common lesion of the cervical spine was osteoarthrosis. The distribution of such lesions is shown in Table 5, from which it can be seen that there is very little difference in prevalence ratios between sexes and that only in the gradient of prevalence ratios with age.

TABle 4. AgE-SEX SPECIFIC PREVALENCE OF RADIOGRAPHIC EVIDENCE SUGGeSTING DEGENERATIVE DISC DISEASE OF THE CERVICAL SPINE, TCHS, 1962-1965

\begin{tabular}{|c|c|c|c|c|c|c|c|c|}
\hline \multirow[b]{2}{*}{$\operatorname{Sex}$} & \multirow{2}{*}{$\begin{array}{l}\text { Age } \\
(y r)\end{array}$} & \multicolumn{5}{|c|}{ Number of persons graded } & \multirow{2}{*}{$\begin{array}{l}\text { Number } \\
\text { filmed }\end{array}$} & \multirow{2}{*}{$\begin{array}{c}\text { valence* } \\
(\%)\end{array}$} \\
\hline & & $\mathbf{0}$ & 1 & 2 & 3 & 4 & & \\
\hline \multirow[t]{7}{*}{ Males } & $16-24$ & 274 & 1 & 0 & 0 & 0 & 275 & 0.0 \\
\hline & $25-34$ & 434 & 11 & 4 & 0 & 0 & 449 & 0.9 \\
\hline & $35-44$ & 476 & 55 & 26 & 10 & 0 & 567 & 6.3 \\
\hline & $45-54$ & 200 & 91 & 69 & 29 & 2 & 391 & 25.6 \\
\hline & $55-64$ & 72 & 40 & 72 & 51 & 7 & 242 & 53.7 \\
\hline & more & 21 & 25 & 44 & 61 & 15 & 166 & 72.3 \\
\hline & Total & 1477 & 223 & 215 & 151 & 24 & 2090 & 18.7 \\
\hline \multirow[t]{7}{*}{ Females } & $16-24$ & 294 & 3 & 0 & 0 & 0 & 297 & 0.0 \\
\hline & $25-34$ & 505 & 6 & 4 & 1 & 0 & 516 & 1.0 \\
\hline & $35-44$ & 545 & 50 & 20 & 6 & 0 & 621 & 4.2 \\
\hline & $45-54$ & 229 & 64 & 51 & 30 & 4 & 378 & 22.5 \\
\hline & $\begin{array}{l}55-64 \\
65 \text { or }\end{array}$ & 111 & 51 & 66 & 36 & 4 & 268 & 39.6 \\
\hline & more & 56 & 24 & 64 & 63 & 23 & 230 & 65.2 \\
\hline & Total & 1740 & 198 & 205 & 136 & 31 & 2310 & 16.1 \\
\hline
\end{tabular}

Numerators of ratios are the sum of numbers in grades 2, 3 and 4 .

Age adjusted prevalence ratios:

Male $=22.3$ per cent.

Female $=15.7$ per cent. 
Evidence for rheumatoid arthritis or of ankylosing spondylitis of the cervical spine was rare. For males, there was only one who had evidence of rheumatoid arthritis, and that of Grade 2 only, for an overall prevalence ratio of 0.04 per cent. For women, there were four with Grade 1 and two with Grade 2, these latter two giving an overall prevalence ratio of 0.07 per cent.

Evidence of ankylosing spondylitis (no grading standard was available for cervical spine) was found in two men for an overall prevalence ratio of 0.1 per cent. One woman had similar changes for an overall prevalence ratio of 0.04 per cent.

Cervical spine lesions of other origins were uncommon. Lesions suggesting a traumatic origin were recorded for 18 men and 7 women, with prevalence ratios of 0.9 per cent and 0.3 per cent, respectively. The most commonly recorded, but not graded, lesions ( 41 or 2.0 per cent in males and 38 or 1.6 per cent in females) were interpreted as developmental in origin. Of this group, the majority showed fusion of adjacent vertebral bodies and their appendages without an intervening disc space, suggesting a failure of segmentation in early embryonic development. There is some suggestion that the prevalence ratios of this type of lesion increase with age in males, but not in females, and because of this fact, some of these lesions may be the end result of trauma or disease rather than developmental defect.

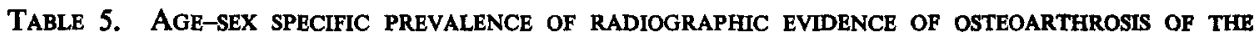
CERVICAL SPINE, TCHS, 1962-1965

\begin{tabular}{|c|c|c|c|c|c|c|c|c|}
\hline \multirow[b]{2}{*}{ Sex } & \multirow{2}{*}{$\begin{array}{c}\text { Age } \\
(\mathrm{yr})\end{array}$} & \multicolumn{5}{|c|}{ Number of persons graded } & \multirow{2}{*}{$\begin{array}{r}\text { Number } \\
\text { filmed }\end{array}$} & \multirow{2}{*}{$\begin{array}{c}\text { Pre- } \\
\text { valence } \\
(\%)\end{array}$} \\
\hline & & 0 & 1 & 2 & 3 & 4 & & \\
\hline \multirow[t]{4}{*}{ Male } & $\begin{array}{l}16-24 \\
25-34 \\
35-44\end{array}$ & $\begin{array}{l}275 \\
438 \\
515\end{array}$ & $\begin{array}{r}0 \\
8 \\
42\end{array}$ & $\begin{array}{r}0 \\
3 \\
10\end{array}$ & $\begin{array}{l}0 \\
0 \\
0\end{array}$ & $\begin{array}{l}0 \\
0 \\
0\end{array}$ & $\begin{array}{l}275 \\
449 \\
567\end{array}$ & $\begin{array}{l}0.0 \\
0.7 \\
1.8\end{array}$ \\
\hline & $\begin{array}{l}45-54 \\
55-64 \\
65 \text { or }\end{array}$ & $\begin{array}{l}264 \\
103\end{array}$ & $\begin{array}{l}73 \\
68\end{array}$ & $\begin{array}{l}51 \\
61\end{array}$ & $\begin{array}{r}3 \\
10\end{array}$ & $\begin{array}{l}0 \\
0\end{array}$ & $\begin{array}{l}391 \\
242\end{array}$ & $\begin{array}{l}13.8 \\
29.3\end{array}$ \\
\hline & older & 43 & 28 & 70 & 24 & 1 & 166 & 57.2 \\
\hline & Total & 1638 & 219 & 195 & 37 & 1 & 2090 & 11.1 \\
\hline \multirow[t]{4}{*}{ Female } & $\begin{array}{l}16-24 \\
25-34 \\
35-44\end{array}$ & $\begin{array}{l}296 \\
515 \\
581\end{array}$ & $\begin{array}{r}1 \\
1 \\
32\end{array}$ & $\begin{array}{l}0 \\
0 \\
8\end{array}$ & $\begin{array}{l}0 \\
0 \\
0\end{array}$ & $\begin{array}{l}0 \\
0 \\
0\end{array}$ & $\begin{array}{l}297 \\
516 \\
621\end{array}$ & $\begin{array}{l}0.0 \\
0.0 \\
1.2\end{array}$ \\
\hline & $\begin{array}{l}45-54 \\
55-64 \\
65 \text { or }\end{array}$ & $\begin{array}{l}274 \\
111\end{array}$ & $\begin{array}{l}70 \\
72\end{array}$ & $\begin{array}{l}29 \\
68\end{array}$ & $\begin{array}{r}5 \\
17\end{array}$ & $\begin{array}{l}0 \\
0\end{array}$ & $\begin{array}{l}378 \\
268\end{array}$ & $\begin{array}{r}9.0 \\
31.7\end{array}$ \\
\hline & older & 58 & 43 & 92 & 36 & 1 & 230 & 56.1 \\
\hline & Total & 1835 & 219 & 197 & 58 & 1 & 2310 & 11.1 \\
\hline
\end{tabular}

*Numerators of ratios are the sum of numbers in grades 2,3 and 4.

Age adjusted prevalence ratios:

Male $=11.6$ per cent.

Female $=10.6$ per cent. 


\section{DISCUSSION}

Estimates have been presented of the prevalence of abnormalities in radiographs of the hands and wrists and cervical spine obtained in a population study. An attempt was made to obtain such radiographs routinely and there was no selection of respondents for radiographic studies on the basis of prior knowledge or suspicion of rheumatic disease. It is thought that these estimates fairly represent the population of the Tecumseh Community Health Study, 20 yr of age or older.

Other factors which may influence the reliability of the estimates presented here include intra- and inter-observer variation; the problem of classification according to some discreet scheme when there is, in fact, a continuous range variation in the event or sign to be classified, and the fact that where two or more types of pathology exist, the evidence of one may overshadow or obscure evidence of the other. A further difficulty is the fact that the Atlas of Standard Radiographs of Arthritis is not as detailed for rheumatoid arthritis as it is for osteoarthrosis.

With these reservations in mind, it is possible to examine the relationship between radiological grading for rheumatoid arthritis and diagnostic classification based on the criteria of the American Rheumatism Association (ARA) [1]. Of the 4 males with grade 2 or greater evidence of rheumatoid arthritis in the hands and wrists, 1 with grade 2 was classified as possible RA, 2 with grade 3 were classified as probable, and the last, with grade 4 , was also classified as probable. Of the 8 females graded 2 or greater, two of those with grade 2 were classified as possible and 1 as probable RA, while the 5 graded 3 or 4 were all classified as definite RA. While these numbers are very small, there is suggestion that females not only have a higher prevalence of $\mathrm{X}$-ray evidence of rheumatoid arthritis, but that in them, the higher radiological grades are associated with greater certainty of clinical diagnosis of rheumatoid arthritis.

Beacause of a major change in the population coverage during the study, not all persons having $\mathrm{X}$-rays also had the detailed type of examination necessary to provide criteria for the ARA classification. This applied to those persons under $35 \mathrm{yr}$ of age, who were not in the special study kindreds. Given this inconsistency, the ratio of $\mathrm{X}$-ray findings suggestive of rheumatoid arthritis were 1 to 47 for males and 1 to 38 for females classified as probable or definite RA by review of the clinical record. These figures suggest that the use of radiographs alone for screening of population for rheumatoid arthritis would not be profitable in terms of the numbers found, the difficulties in interpretation, the cost to the survey, and, not least, the cost to the examined in additional ionizing radiation.

The prevalence of radiologic evidence of rheumatoid arthritis in the hand and wrist films in the population is lower than that reported by Lawrence and others [2] in the hands and feet of population samples from eight geographic areas. These authors reported prevalence rates ranging from 0.9 to 12.1 per cent for radiological evidence of erosions of grade 2 or greater in the hands and/or feet of subjects aged 35-64 yr. The corresponding rate for all Tecumseh subjects aged 35 and over, based on hand and wrist films only, is 0.42 per cent. This difference doubtless reflects the not infrequent presence of erosive radiographic changes in the feet. That it may also reflect, in part at least, inter-observer variation is suggested by the fact that Lawrence, interpreting a subsample of $\mathbf{4 0 0}$ films for the Tecumseh Study, of persons $35 \mathrm{yr}$ or older, reported a prevalence of grade 2 or greater erosive arthritis in 1.7 per cent [3]. The fact that grade 2 or greater erosive disease was reporte 1 more frequently in males $(2.7$ per 
cent) than in females ( 0.7 per cent) is in contrast to the present report. Among Tecumseh subjects $35 \mathrm{yr}$ of age and over, 0.3 per cent of males and 0.5 per cent of females were graded 2 or greater for radiological evidence of rheumatoid arthritis in the present study. This discrepancy would suggest a systematic difference between observer groups in the assignment of radiological abnormalities to rheumatoid arthritis as opposed to osteoarthrosis and other causes.

Radiologic evidence of rheumatoid arthritis in the cervical spine was very rare. Grade 2 changes were observed in one male with no other diagnostic criteria and in two females, both of whom were classified as possible RA by the ARA criteria.

The two men and one woman considered to have radiologic evidence of ankylosing spondylitis in the cervical spine had none of the diagnostic criteria for rheumatoid arthritis.

While these prevalence ratios for radiologic evidence of rheumatoid arthritis and ankylosing spondylitis are very low, they may underestimate the true prevalence, because of the possibility that lesions due to these disorders may be obscured by lesions of more common conditions, such as osteoarthrosis or degenerative disc disease. However, it is felt that these data do provide an indication of the relative frequency of radiologic abnormalities attributable to rheumatoid arthritis in the hands and wrists and cervical spine and of their relationship to sex and age. These results suggest that few cases of rheumatoid arthritis would fail to be detected by clinical examination in population studies not employing routine radiologic examinations.

Radiographic evidence of degenerative join disease was much more common; osteoarthrosis of the hands and wrists, degenerative disc disease of the cervical spine, and osteoarthrosis of thecervical spine being observed in decreasing order of frequency. Osteoarthrosis of the hands and wrists was noted in younger age groups in males, increased in prevalence with age in both sexes, and, among all subjects age $16 \mathrm{yr}$ and older was somewhat more common in women. This pattern, as well as the prevalence rates, is very similar to that reported by Soila and Pyykonen [4] for the hands and wrists of 4793 patients, ages $20-79 \mathrm{yr}$. The present results are also remarkably similar to those reported from the National Health Survey in which 20.3 per cent of both men and women age 18-79 were found to have mild, moderate or severe osteoarthritis of the hands [5]. These prevalence ratios are somewhat lower than those reported by Lawrence, Brenner and Bier [6] for samples of the Leigh and Wensleydale populations, largely due to the fact that multiple joints were X-rayed in the latter study.

Radiographic evidence of degenerative disc disease in the cervical spine also showed a direct relationship between increasing prevalence and advancing age; the overall prevalence was slightly higher in men than in women. Osteoarthrosis of the cervical spine occurred with equal frequency in males and females, but appeared to manifest itself somewhat earlier in males; in both sexes the frequency rose with increasing age. This pattern is again similar to that reported by Soila and Pyykonen [4] for 'osteochondrosis' of the cervical spine, although the prevalence ratios are somewhat lower for all age-sex groupings in the present study. The frequency of disc degeneration in the cervical spine among subjects in the age range 55-64 yr is approximately 15-20 per cent lower than that reported by Kellgren and Lawrence [7] for a sample of the population of Leigh in this age group; in both populations males were affected more frequently.

'Other' abnormalities observed in the radiographs have been dealt with only in 
broad classes. While these are not strictly rheumatic diseases, they may, nonetheless, impair joint function to some extent. The most common of these lesions were attributable to trauma, especially in the hands and wrists of males. Amputation of one or more digits was observed with some frequency; although the records have not yet been reviewed for the pertinent history in these cases, it is true that the principal industry and largest employer in Tecumseh is a firm manufacturing compressors, an industry using heavy machinery and offering many potentialities for trauma to the hands.

Lesions attributed to developmental defects were observed in 1.5-2.0 per cent of subjects; the most common of these occurred in the cervical spine where adjacent vertebral bodies were fused without any evidence of an intervening disc space, suggesting a failure of segmentation during embryonic life as the most probable cause.

\section{SUMMARY}

Radiographs of the hands and wrists and cervical spine of 4415 residents of Tecumseh, Michigan, aged $16 \mathrm{yr}$ and over, have been reviewed. Evidence of rheumatoid arthritis was observed in the hands and wrists of 0.19 per cent of males and 0.34 per cent of females. The prevalence of cervical spine changes, which could be attributed to rheumatoid arthritis or ankylosing spondylitis, was insignificant.

Degenerative changes in both examined regions occurred much more frequently and showed a marked positive correlation with advancing age. Radiographic evidence of osteoarthrosis of the hands and wrists was observed in 19.5 per cent of males and 23 per cent of females. In the cervical spine, degenerative disc disease (16-19 per cent) was noted somewhat more frequently than osteoarthrosis (11 per cent).

Among the other radiographic lesions which were observed, those of post traumatic changes, including amputation of digits, in the hands and wrists and fusion of cervical vertebral bodies, thought to represent a failure of segmentation in embryonic life, were most frequent.

\section{REFERENCES}

1. Ropes MW, Bennett GA, Cobb S, et al: 1958 revision of diagnostic criteria for rheumatoid arthritis. Bull Rheum Dis 9: 175-176, 1958

2. Lawrence JS, Behrend T, Bennet PH, et al: Geographical studies on rheumatoid arthritis. Ann Rheum Dis 25: 425-432, 1966

3. Lawrence JS: Geographical studies of rheumatoid arthritis. Chap 6 in: Population Studies in Rheumatic Diseases. Amsterdam, Excerpta Medica Foundation, 1968

4. Soila P, Pyykonen L: Tables of incidence of osterochondrosis in joints. Acta Rheum Scand 6: $151-160,1960$

5. National Center for Health Statistics: Prevalence of Osteoarthritis in adults by age, sex, race, and geographic area, United States 1960-1962. Vital and Health Statistics. PHS Pub. No. 1000Series 11-No 15. Public Health Service, Washington, US Government Printing Office, 1966

6. Lawrence JS, Bremer JM, Bier F: Osteoarthrosis. Ann Rheum Dis 25: 1-24, 1966

7. Kelgren JH, Lawrence JS: Osteoarthrosis and disc degeneration in an urban population. Ann Rheum Dis 17: 388-397, 1958 